\title{
The Impact of the Two Infographics Types in Terms of Presentation on Developing the Cognitive and Performance Aspects of Digital Graphics Design Skills and Motivation Towards them among Students of Educational Technology at The University of Jeddah
}

\author{
Hosam Abdulhameed Althibyani \\ Faculty of Education - Umm Al-Qura University - KSA \\ Email: halthibyani@uj.edu.sa
}

\begin{abstract}
The aim of this research is to reveal the effect of the interaction between the two types of Infographics in terms of presentation (static, motion) in developing digital graphics design skills and motivation towards it among undergraduate students in the Department of Educational Technology, College of Education, University of Jeddah, Saudi Arabia. To achieve this, the experimental method was used, and the research was applied to a sample of 109 students, who were divided into four experimental groups according to the infographic technique used in education. The study reached a number of results, the most important of which is the absence of statistically significant differences at the level $(\alpha<0.05)$ between the two types of Infographics in terms of presentation method (static, motion) in the development of cognitive aspects and performance aspects of digital graphic design skills and motivation towards them among students of Educational Technology in experimental groups at the University of Jeddah. In addition, there were no statistically significant differences at the level ( $\alpha$ $<0.05$ ) between the two types of Infographics in terms of presentation (static, motion) in developing motivation towards digital graphics among students of Educational Technology in experimental groups at the University of Jeddah. In light of these results, the research recommended the necessity of employing infographic technology in its fixed and mobile modes in teaching the digital graphics course and other courses, and in presenting the cognitive and performance structure of the course content to students, because of its significant impact on the development of performance and cognitive skills and raising the efficiency of education compared to traditional methods.
\end{abstract}

Keywords: Static Infographics, Motion Infographics, Cognitive and Performance Skills, Digital Graphic Design Skills, Motivation. 


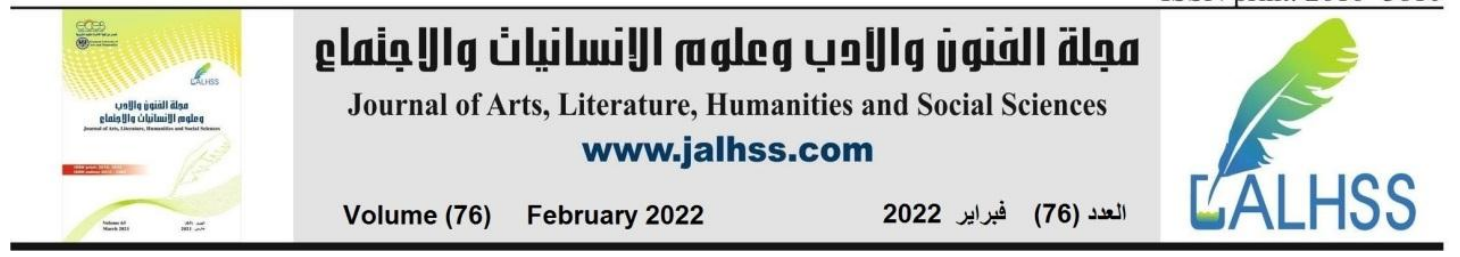

\section{Introduction}

The information and knowledge inflation that the world is witnessing recently in this modern era has led to moving towards searching for modern means of communication and technologies through which the human mind is enabled to perceive this huge amount of information and knowledge in easy, flexible and more efficient ways. That is by relying on modern technologies that rely in their essence on visual communication, as visual communication has become a necessity that cannot be ignored in designing the data and information that individuals are exposed to on a daily basis (Ahmed et al., 2018, p. 2).

Visual communication may help in forming an effective learning pattern represented by the visual learning pattern; In which the learner depends on visual perception and visual memory. The learner learns through many visual means, such as drawings, shapes, graphic representations, pictorial presentations, and other visual techniques whose presence has become a necessity to improve the educational process and develop cognitive experiences (Afaneh and Al-Waeli, 2016, pg. 748).

The major trend was towards using computer and information technologies in the learning and teaching processes with the aim of qualifying learners to deal with the changes and developments of the technical age. This requires teaching them how to access knowledge from its various sources on their own, as well as developing their capabilities and refining their skills in dealing with various such technologies and educational means such as infographics, media and other modern visual technologies (Ahmed et al., 2018, p. 2). The main function of the infographic technology is to embody the data by converting it into visual forms that enable the recipient to derive meanings and messages in a smooth and easy way, especially as it has an aesthetic appeal that attracts attention and provides an enjoyable visual experience (Purchase \& Moere, 2011, p2).

The infographic technology works to give an attractive visual form to the educational content, and to collect and display information in a concise manner, which helps the learner to understand complex data and information easily. It also helps those in charge of the educational process to transfer information and provide educational content in an interesting way, which prompted many educational institutions and universities to adopt this technology and invest it in serving the educational process and integrating it into academic curricula (Ashman \& Patterson, 2015, p 619). Crooks, Lankow, \& Ritchie (2011: p42) mentions that infographic technology was not only used in the educational process, but was also employed in marketing and commercial advertising. Many brands are looking to capture the interest of customers by using this technology in defining and describing a product or service, which contributes to improving sales.

Infographic technology is a tool for converting complex data into graphics that are easier for the learner to deal with and absorb more effectively, which made it an important and essential tool for teachers, lecturers and learners, because it provides them with the intellectual skills necessary to move them to the stage of analysis and criticism, and enhance the skills of instructional design on both sides of the educational process. 


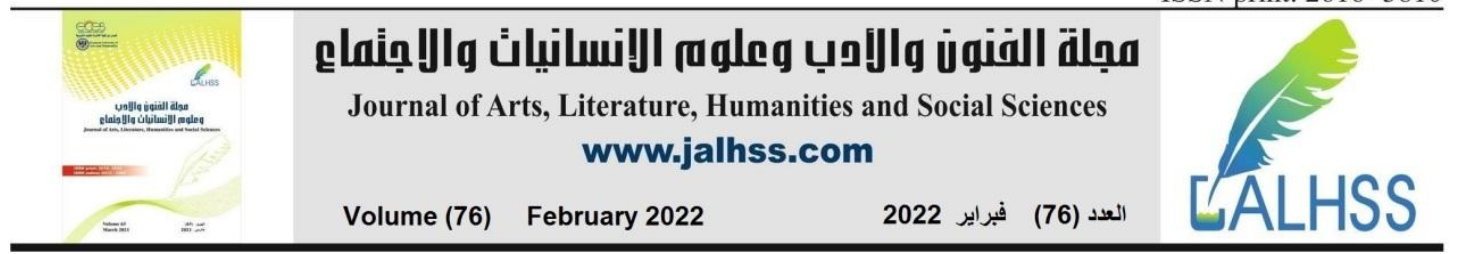

This made this technology and its patterns (static, motion, and interactive) one of the present and future requirements in the world of education (Morsi, 2017: p. 45).

Several studies and research have confirmed the role of using infographic technology and its impact on the cognitive and performance aspects of some of the different skills of learners, such as the study of: Smiciklas (2012); Akkoyunlu \& Kibar (2014); Abu Asbeh (2015); Ott, Robins \& Shephard (2012). Abu Osba (2015); Abu Zeid (2016); Morsi (2017); Al Shaya and Al Zahrani (2018), and other studies.

\subsection{Research Problem}

Reliance on visual communication methods -including infographic technology- has become currently as a means of transmitting messages and information, as well as a means of discourse and a reinforcement of cultural identity (National Education Association, 2001, p2). The results of several previous research and studies, which revealed the impact of the use of educational infographics in developing some of the cognitive and performance aspects of learners' skills in e-learning environments, is among the main motives for conducting this study, including the following studies: Kos \& sims (2014), Noh et al. (2015), Darwish and Al-Dakhni (2015), Darwish (2016), Abeer Abu Oriban (2017), Sears (2012), Al-Jeriwi (2014), Kos \& sims (2014) and Noh et al. (2015), and Ott, Robins \& Shephard (2015). The literature indicated that the static educational infographic type is more effective compared to the motion infographic type. While the results of the studies of Crooks, Lankow \& Ritchie (2012; Abu Asba (2015) and Gebre \& Polman (2015), which found that the motion educational infographic type was more effective compared to the static educational infographic type.

In light of the different results of some previous studies and research that dealt with the use of educational infographics and their impact on the development of some cognitive and performance aspects; It was necessary to conduct this study to reveal the effect of using the two educational infographics patterns (static, motion) in improving learning outcomes and developing learners' performance skills. In addition, most of the studies -according to the researcher's knowledge- did not address the detection of the impact of the two types of infographics in terms of presentation in developing the cognitive and performance aspects of digital graphics design skills and the motivation towards them among students of Educational Technology at the University of Jeddah. It also became clear through the researcher's work in the Department of Educational Technology that there are difficulties among some learners in acquiring some cognitive and performance aspects of digital graphic design skills, which may be due to some academics' omission to use visual educational techniques or using techniques that may not motivate learners towards acquisition of those knowledge and skills. In light of the aforementioned justifications, the need to conduct this study came to reveal the impact of the two types of infographics in terms of presentation in developing the cognitive and performance aspects of digital graphics design skills and motivation towards them among students of Educational Technology at the University of Jeddah. Therefore, the problem of the current study is being in the following main question: 
- What is the effect of the two infographics types in terms of presentation in developing the cognitive and performance aspects of digital graphics design skills and the motivation towards them among students of Educational Technology at the University of Jeddah?

\subsection{Research Aim}

The current research seeks to investigate the effect of two infographics styles in terms of presentation in developing the cognitive and performance aspects of digital graphics design skills and motivation towards them among students of Educational Technology at the University of Jeddah.

\subsection{Research Importance}

The importance of the study is represented in seeking to reveal the impact of the interaction between the two educational infographics styles (static, motion) in developing the cognitive and performance aspects of digital graphics design skills and motivation towards them. This is evident in the following:

1- The importance of the current research lies in the fact that it is the latest of its kind, because Arabic studies in general, and local studies in particular -according to the researcher's knowledge- are not touched on the effect of the interaction between educational infographic types in developing the cognitive and performance aspects of digital graphics design skills and motivation towards them.

2- The current research helps highlight the importance of using educational infographics in teaching the digital graphics course in particular and other courses in general, and spreading knowledge in higher education institutions and universities, which helps officials and decision makers in the Ministry of Education to adopt this technical innovation in education.

3- The conclusions of the current research can be used to guide faculty members to use digital graphics in education for students in the current age of visual communication.

4- The results of the current research may help the designers of electronic courses to use the educational infographic style that is most attractive to learners, which gives them the greatest pleasure and suspense in the learning process.

\subsection{Research Limits}

The current research is limited to the following limits:

1. Human limits: a random sample of (109) students from the Department of Educational Technology at the College of Education at the University of Jeddah.

2. Objective limits: The effect of two infographics types in terms of presentation in developing the cognitive and performance aspects of digital graphics design skills and motivation towards them among students of Educational Technology at the University of Jeddah.

3. Spatial limits: Department of Educational technology, College of Education, University of Jeddah, Kingdom of Saudi Arabia.

4. Time limits: The study was conducted in the first semester of the academic year (1440-1441 AH). 


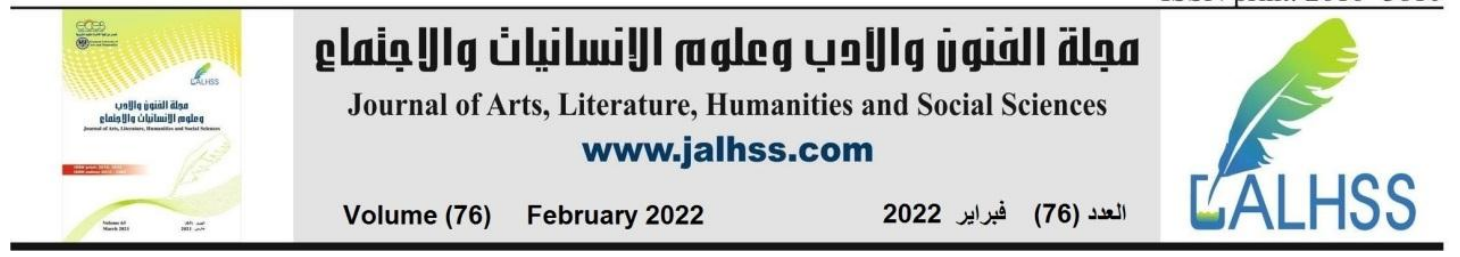

\subsection{Research Terms}

\section{1- Effect:}

The effect is defined idiomatically as: what produced from the thing, and the rest of the thing, which is the result and the outcome of the thing, meaning the sign and what indicates the existence of the thing (Ibn Manzur, 1998). With regard to the effect of using infographics, the effect was defined by Al-Shay'i and Al-Zahrani (2018: p. 89), as: the result that we will get after applying the infographic type on students, by measuring the result through tests designed for this purpose.

\section{2- Static Infographic:}

Al-Otaibi (2018: p. 32) gave a definition of a static infographic as: a static design its content is chosen by the designer, or the party that produces it, and contains information on a specific topic, in the form of images and graphics that are easy to understand. There are many forms for it such as printed forms or graphic designs spread on Internet pages.

\section{3- Motion Infographic:}

Hassan (2016: p. 64) defined it as: a visual presentation of information and data that mixes words, graphics and images in one frame in an organized and concise manner, and those words, graphics and images are animated. As for Krum (2013, p33), he defined it as a communication tool full of visual and audio stimuli in the form of twoor three-dimensional animations, which attracts the viewer's attention all the time. In addition, the narration accompanying those animations helps the viewer to discover and absorb the information provided by the infographic, which provides an excellent learning environment to explain a complex topic.

\section{4- Motivation:}

Khadija and Al-Zahraa (2015: p. 19) have indicated that motivation is a state of arousal and internal psychological tension. It may be consciously or unconsciously. It stimulates behavior and drive the individual to carry out activities, actions and behaviors with the intent for achieving a specific goal of satisfying different needs, in order to relieve stress and boredom and restore balance to behavior and self in general, and it is associated with many synonyms, such as incentives, needs, motive, habit, emotion, and value.

\section{5- Digital Graphics:}

Carson (2003, p368-369) defined it as: visual representations of data, information, and knowledge through graphics, static and moving illustrations, and videos, usually prepared by computers or smart devices.

Digital graphics are defined procedurally as: A motion or static images, or video clips that learners in the Department of Educational Technology at the University of Jeddah design using Adobe Photoshop, in order to collect and display information in a concise manner, and to give an attractive visual shape to the educational content, which helps the learner to understand and assimilate complex data and information more easily. 


\section{6- Skills of Digital Graphics Design:}

Ozdamli \& Ozdal ((2018, p1198-1199) defines digital graphics design skills as: a set of skills required in visual interpretation and formation of visual messages according to specific design standards, and it includes skills such as determining the size and nature of visual materials, effective use of visual media, as well as skills Design and build unique, meaningful visual media.

\section{Research Method}

Based on the nature of the current study, and in order to achieve its objectives, the experimental approach with a semi-experimental design was mainly used to determine the impact of the interaction between the two types of infographics in developing the cognitive and performance aspects of digital graphics design skills and motivation towards them among students of Educational Technology at the College of Education at the University of Jeddah.

\subsection{Research Population and Sample}

The research population means: "All individuals, people or things who are the subject of the research problem" (Obaidat and others, 1996, p. 219). The current study population consists of all students of the Department of Educational Technology at the College of Education at the University of Jeddah in the Kingdom of Saudi Arabia. A random sample of (109) students was selected from the research community, Department of Educational technology, College of Education, University of Jeddah in the Kingdom of Saudi Arabia. As they were divided into four groups, two experimental groups apply the static educational infographic and two groups apply the motion educational infographic, and accordingly we have four experimental groups; (G1) Static infographic style, (G2) Static infographic style, (G3) Motion infographic style, (G4) Motion infographic style

\subsection{Research Hypotheses}

H1: There are no statistically significant differences at the level $(\alpha<0.05)$ between the two types of infographics in terms of presentation (static, motion) in developing the cognitive aspects of digital graphics design skills for students of Educational Technology in the groups Experimental at the University of Jeddah.

$\mathrm{H} 2$ : There are no statistically significant differences at the level $(\alpha<0.05)$ between the two types of infographics in terms of presentation (static, motion) in developing the performance aspects of digital graphics design skills for students of Educational Technology in the groups Experimental at the University of Jeddah.

H3: There are no statistically significant differences at the level $(\alpha<0.05)$ between the two types of infographics in terms of presentation (static, motion) in developing motivation towards digital graphics among students of Educational Technology in experimental groups at the University of Jeddah.

\section{Research Results}

\subsection{Results of the First Hypothesis}

To test first hypothesis, the researcher relied on the results of comparing the pre-test of the two experimental groups $(\mathrm{G} 1+\mathrm{G} 2)$ that will be taught using the static 


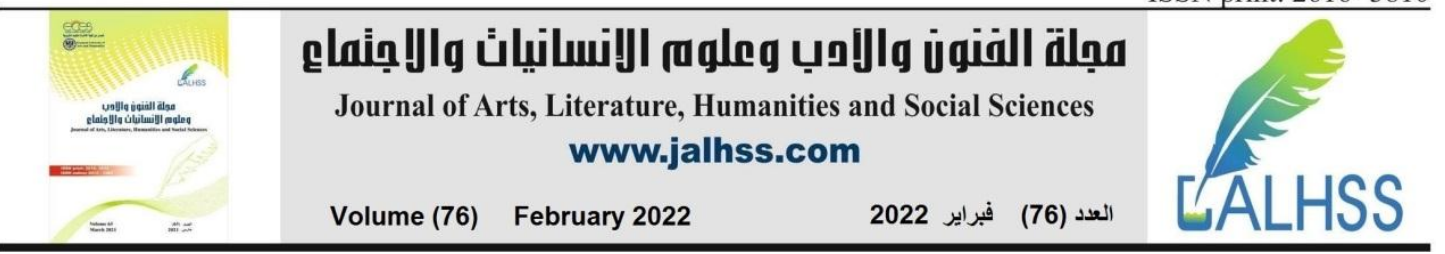

infographic type, and the two experimental groups $(\mathrm{G} 3+\mathrm{G} 4)$ that will be taught in the motion infographic type, with the results of the post-test of the same groups in the achievement test. That is for identifying the impact of the educational infographic style (static and motion) on developing the cognitive aspects of digital graphics design skills.

The researcher used the (Paired Sample T test) to detect the impact of using the static infographic type in developing the cognitive aspects of digital graphics design skills (educational achievement), by calculating the significance of the difference between the mean scores of students' test in the pre- and post- applying of the two experimental groups (M1 + M2) that used the fixed infographic, as shown in table (1).

Table 1: Test (Paired Sample $T$ test) of the significant of the differences between the mean of the pre- and post-applying of the two experimental groups (G1 + G2) that used the static infographic in the achievement test $(n=55)$.

\begin{tabular}{|l|l|l|l|c|}
\hline Groups & $\begin{array}{l}\text { Arithmetic } \\
\text { mean }\end{array}$ & $\begin{array}{l}\text { Standard } \\
\text { deviation }\end{array}$ & T & $\begin{array}{l}\text { Significance } \\
\text { level at } \alpha<0.05\end{array}$ \\
\cline { 1 - 3 } Pre & 17.6364 & 5.64822 & \multirow{2}{*}{8.025} & $\begin{array}{c}0.000 \\
\text { (Significant) }\end{array}$ \\
\hline Post & 24.7818 & 7.34013 & &
\end{tabular}

By reviewing the results in table (1), we find that the calculated (t) value is (8.025), which is greater than the tabular $(\mathrm{t})$ value at the $(0.05)$ level, which indicates that there is a statistically significant difference at the significance level $(\alpha<0.05)$ between the scores mean of the total sample members in the pre-applying, which is (17.6364), and the scores mean of the sample members in the post-applying, which is (24.7818). This difference is in favor of the higher mean, which is the average of the post-application scores. This indicates that there is an effect of using the static infographic type in developing the cognitive aspects of digital graphics skills, compared to not using it, that is the reliance on traditional methods of teaching. Figure (1) shows the differences between the means in favor of the post-applying's scores of the static infographic.

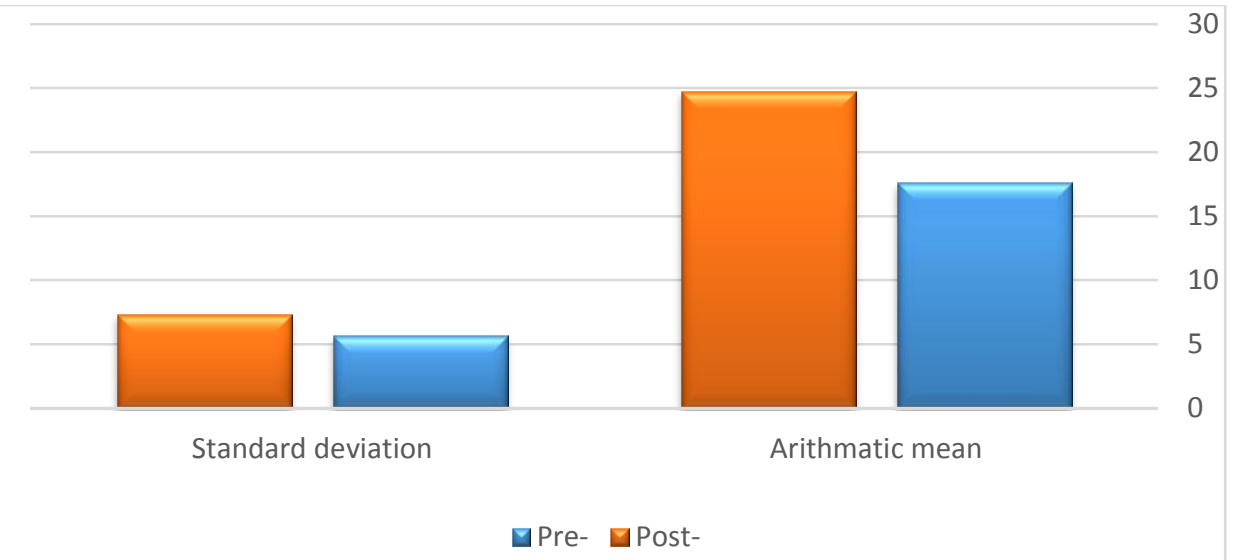

Figure 1: The significance of the differences between the mean of the pre- and postapplying of the two experimental groups (G1 + G2) that used the static infographic in the achievement test 


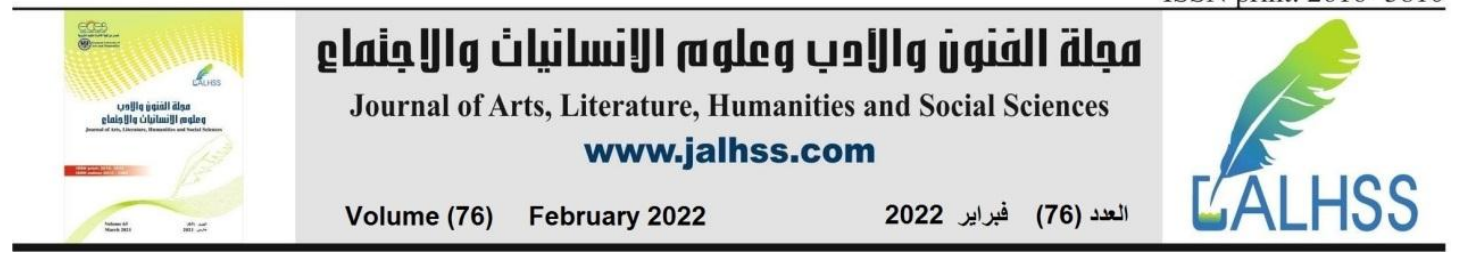

Paired Sample T test was using in order to identify the effect of using the motion infographic type in developing the cognitive aspects of digital graphics design skills (educational achievement). That is by calculating the significance of the difference between the mean test scores of students in the pre and post applying of the two experimental groups $(\mathrm{G} 3+\mathrm{G} 4)$ that used the motion infographic using as shown in table (2).

Table 2: Test (Paired Sample T test) of the significant of the differences between the mean of the pre- and post-applying of the two experimental groups (G1 + G2) that used the motion infographic in the achievement test $(n=55)$.

\begin{tabular}{|l|l|l|c|c|}
\hline Groups & $\begin{array}{l}\text { Arithmetic } \\
\text { mean }\end{array}$ & $\begin{array}{l}\text { Standard } \\
\text { deviation }\end{array}$ & T & $\begin{array}{l}\text { Significance } \\
\text { level at } \alpha<0.05\end{array}$ \\
\hline Pre & 16.8333 & 7.08906 & 6.033 & $\begin{array}{c}0.000 \\
\text { (Significant) }\end{array}$ \\
\hline Post & 22.4815 & 7.29627 & 6 \\
\hline
\end{tabular}

By reviewing the results in table (2), we find that the calculated (t) value is (6.033), which is greater than the tabular (t) value at the (0.05) level, which indicates that there is a statistically significant difference at the significance level $(\alpha<0.05)$ between the scores mean of the total sample members in the pre-applying, which is (16.8333), and the scores mean of the sample members in the post-application, which is (22.4815). This difference is in favor of the higher mean, which is the average of the post-applying scores, which indicates that there is an impact of using the motion infographic type in developing the cognitive aspects of digital graphics skills compared to not using it, which is the reliance on traditional methods of teaching. Figure (2) shows the differences between the means in favor of the post-applying's scores of the motion infographic.

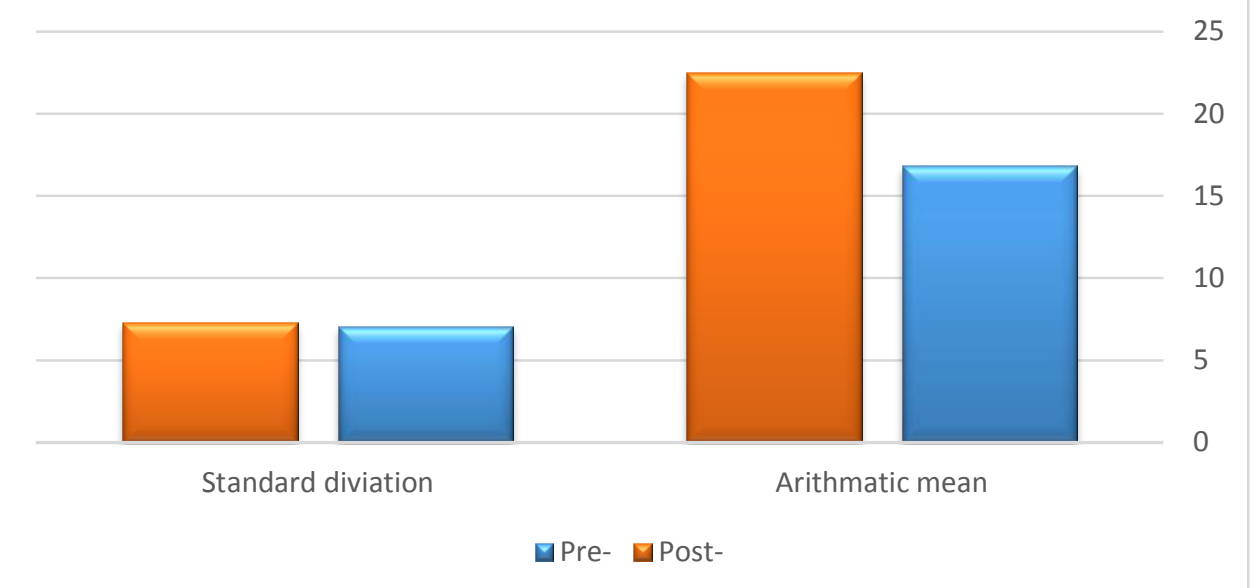

Figure 2: The significance of the differences between the mean of the pre- and postapplying of the two experimental groups (G1 + G2) that used the motion infographic in the achievement test

Finally, in order to reveal the impact of the difference in the use of static and motion infographics types in developing the cognitive aspects of digital graphics design skills (academic achievement), the independent sample $\mathrm{T}$ test was used to calculate the significance of the difference between the mean scores of students' test 


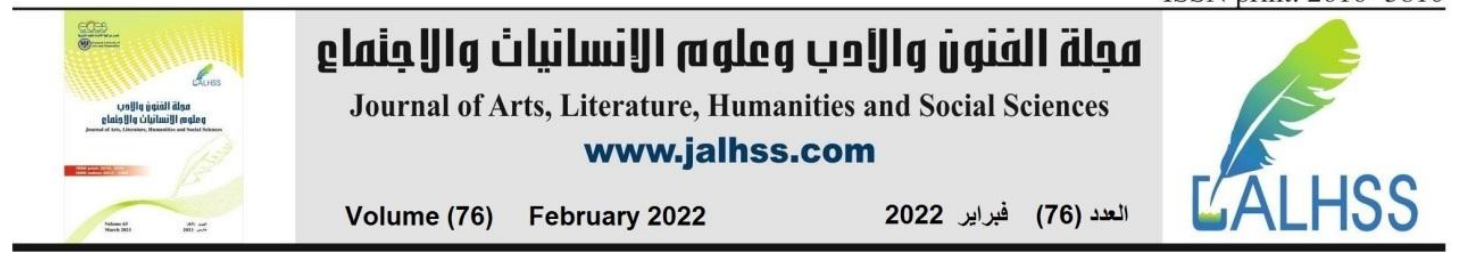

in The two experimental groups $(\mathrm{G} 1+\mathrm{G} 2)$ that used static infographics, and the two experimental groups (G3 + G4) that used motion infographics, in the degrees of the post-applying of the achievement test, as shown in table (3).

Table 3:Results of the independent samples t-test to indicate the differences between the mean scores of the experimental groups (G1 + G2) and the experimental groups (G3 + G4) in the post-applying of the achievement test $(n=109)$

\begin{tabular}{|l|l|l|l|l|l|}
\hline Groups & $\#$ & $\begin{array}{l}\text { Arithmetic } \\
\text { mean }\end{array}$ & $\begin{array}{l}\text { Standard } \\
\text { deviation }\end{array}$ & T value & $\begin{array}{l}\text { Significance } \\
\text { level at a } \\
\alpha<0.05\end{array}$ \\
\hline G1+G2 & 55 & 24.7818 & 7.34013 & 1.641 & $\begin{array}{l}0.104 \\
\text { (Not } \\
\text { significant) }\end{array}$ \\
\hline
\end{tabular}

It is clear from Table (3) that there are no statistically significant differences at the level of significance $(\alpha<0.05)$ between the means of the two experimental groups $(\mathrm{G} 1+\mathrm{G} 2)$ that will be taught using the static infographic type, and the two experimental groups $(\mathrm{G} 3+\mathrm{G} 4)$ that will be taught using motion infographic type in the degrees of the post-applying of the achievement test. The value of $(t)$ was $(1,641)$ at the significance level (0.104), which is greater than the statistical significance level (0.05). Figure (3) shows the convergence of differences between the averages of the two experimental groups $(\mathrm{G} 1+\mathrm{G} 2)$ and the two experimental groups $(\mathrm{G} 3+\mathrm{G} 4)$, and there are no statistically significant differences between them.

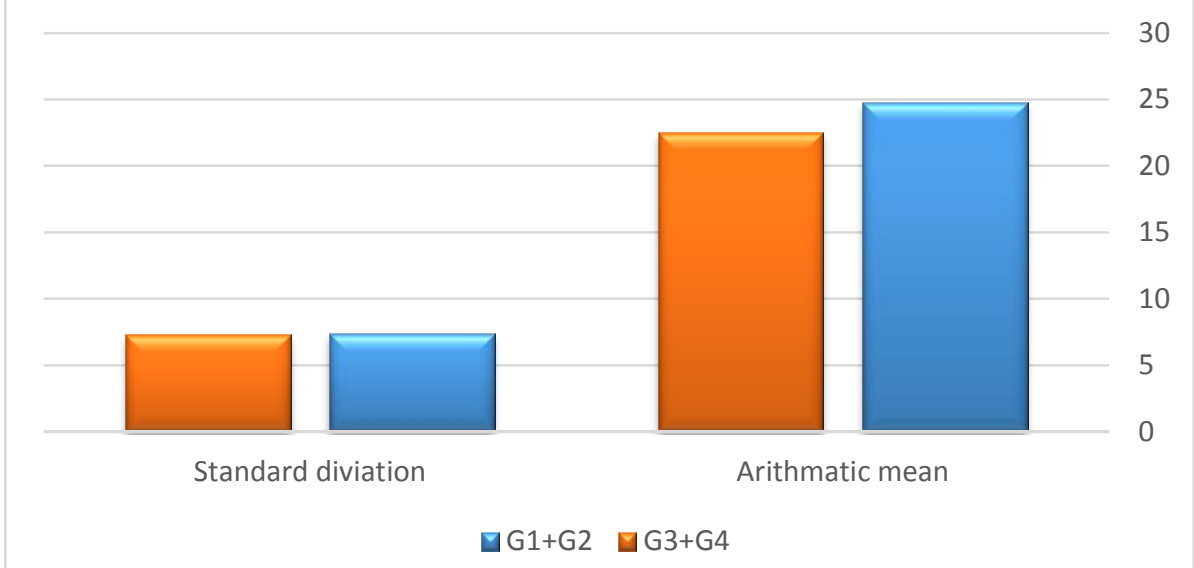

Figure 3:The significance of the differences between the mean scores of the experimental groups (G1 + G2) and the experimental groups (G3 + G4) in the post-applying of the achievement test

In light of the above, the hypothesis was accepted, which states that "There are no statistically significant differences at the level $(\alpha<0.05$ between the two types of infographics in terms of presentation (static, motion) in developing the cognitive aspects of skills digital graphics design for Educational Technology students in experimental groups at the University of Jeddah".

\subsection{Results of the Second Hypothesis}

To test second hypothesis, the researcher resorted to relying on the results of comparing the observation card and the results evaluation card for the two 


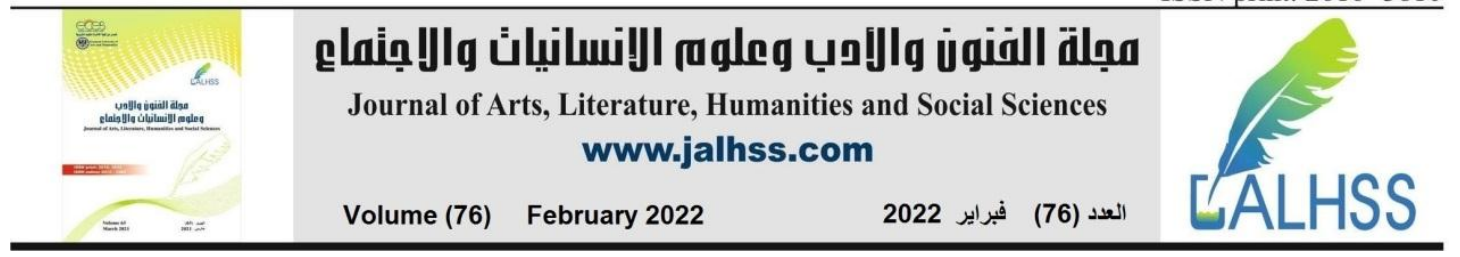

experimental groups $(\mathrm{G} 1+\mathrm{G} 2)$ that will study using the static infographic type, and the two experimental groups $(\mathrm{G} 3+\mathrm{G} 4)$ that will study using the motion infographic type, with the results of the observation card and the results evaluation card for the same groups, to identify the impact of the educational infographic style (static, motion) on developing of the performance aspects of digital graphics design skills.

The researcher used the (Paired Sample T test) to detect the effect of using the static infographic type in developing the performance aspects of digital graphics design skills (observation card and results evaluation card). That is by calculating the significance of the difference between the average scores of the observation card and results evaluation card in the pre and post applying of the two experimental groups $(\mathrm{G} 1+\mathrm{G} 2)$ that used the static infographic, as shown in the tables (4) and (5).

Table 4: Paired sample $T$ test to indicate the differences between the mean of the pre and post applying of the two experimental groups (G1 + G2) that used the static infographic in the observation card $(n=55)$.

\begin{tabular}{|l|l|l|l|c|}
\hline Groups & $\begin{array}{l}\text { Arithmetic } \\
\text { mean }\end{array}$ & $\begin{array}{l}\text { Standard } \\
\text { deviation }\end{array}$ & T & $\begin{array}{l}\text { Significance } \\
\text { level at } \alpha<0.05\end{array}$ \\
\cline { 1 - 3 } Pre & 29.9818 & 18.79469 & \multirow{2}{*}{-83284} & $\begin{array}{c}0.000 \\
\text { (Significant) }\end{array}$ \\
\hline Post & 68.6182 & 28.26494 & &
\end{tabular}

By reviewing the results in table (4), it becomes clear that the calculated (t) value is (-8.284) which is greater than the tabular (t) value at the (0.05) level, which indicates the existence of a statistically significant difference at the significance level $(\alpha<0.05)$ between the average scores of the total sample members in the pre-applying of the observation card, which amounted to (29.9818) and the average scores of the sample members in the post-applying of the observation card, which amounted to (68.6182). This difference is in favor of the higher average, which is the average of the post-applying scores, which indicates the existence of an effect of using the static infographic type in developing the performance aspects of digital graphics skills compared to not using them in terms of the results of the observation card. Figure (4) shows the differences between the performance averages in favor of the post-applying degrees of the static infographic in the observation card. 

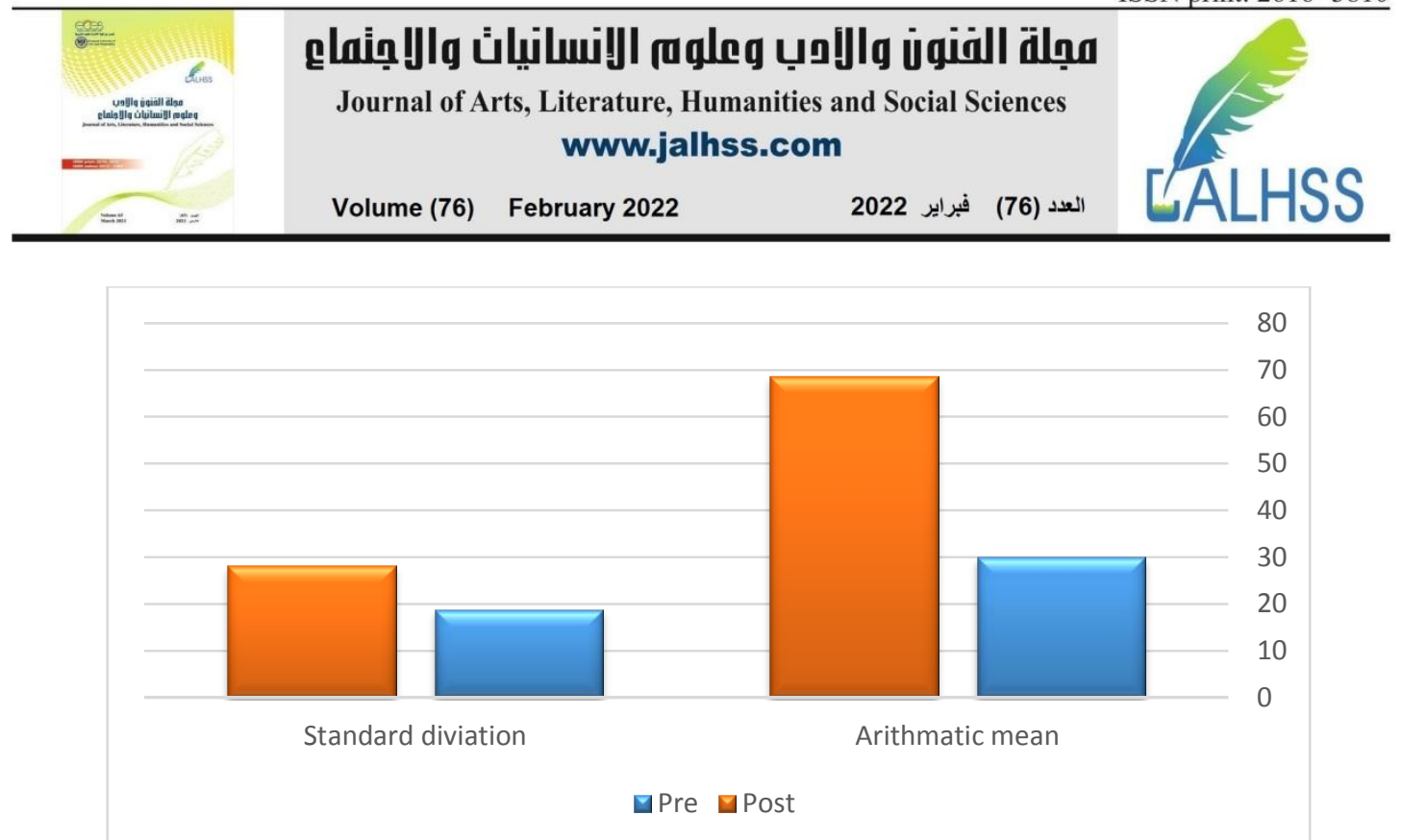

Figure 4: The significance of the differences between the mean of the pre and post applying of the two experimental groups (G1 + G2) that used the static infographic in the observation card.

To ensure these differences in the performance aspects, the differences between the arithmetic means of the results evaluation card scores were also compared in the pre and post applying of the two experimental groups $(\mathrm{G} 1+\mathrm{G} 2)$ that used the static infographic, using a (Paired Sample T test). It is shown in the table (5).

Table 5:Paired sample $T$ test to indicate the differences between the mean of the pre and post applying of the two experimental groups (G1 + G2) that used the static infographic in the results evaluation card $(n=55)$.

\begin{tabular}{|l|l|l|c|c|}
\hline Groups & $\begin{array}{l}\text { Arithmetic } \\
\text { mean }\end{array}$ & $\begin{array}{l}\text { Standard } \\
\text { deviation }\end{array}$ & T & $\begin{array}{l}\text { Significance } \\
\text { level at } \alpha<0.05\end{array}$ \\
\cline { 1 - 3 } Pre & 27.3636 & 18.05995 & \multirow{2}{*}{-7.672} & $\begin{array}{c}0.000 \\
\text { (Significant) }\end{array}$ \\
\hline Post & 50.5455 & 15.75133 & &
\end{tabular}

By reviewing the results in table (5), it becomes clear that the calculated (t) value amounted to (-7.672), which is greater than the tabular $(\mathrm{t})$ value at the level $(0.05)$. This indicates that there is a statistically significant difference at the significance level $(\alpha<0.05)$ between the average scores of the total sample members in the pre-applying of the results evaluation card, which is (27.3636) and the average scores of the sample members in the post-applying, which is (50.4555) in favor of the higher average, which is the average score post-applying. This indicates that there is an effect of using the static infographic type in developing the performance aspects of digital graphics skills, compared to not using it in terms of the outcomes of the results evaluation card. Figure 5 shows the differences between the performance averages in favor of the postapplying scores of the static infographic in the results evaluation card. 

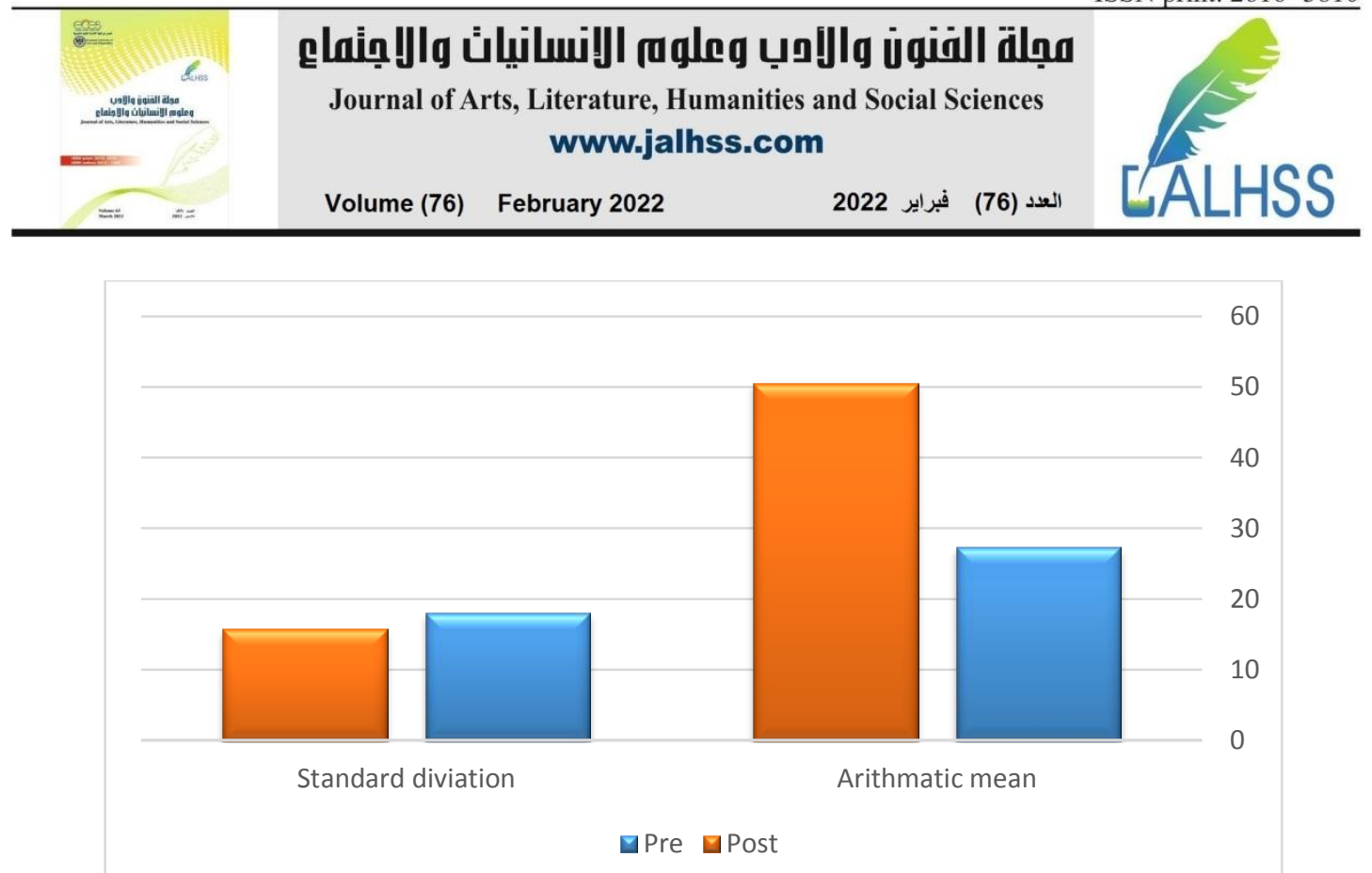

Figure 5: The significance of the differences between the mean of the pre and post applying of the two experimental groups (G1 + G2) that used the static infographic in the results evaluation card.

The effect of using the motion infographic type in developing the performance aspects of digital graphics design skills was identified, through calculating the significance of the difference between the mean scores of the observation card and the results evaluation card in the pre and post applying of the two experimental groups $(\mathrm{G} 3+\mathrm{G} 4)$ that used the motion infographic using (Paired Sample T test). That is shown in the tables (6) and (7).

Table 6: Paired sample $T$ test to indicate the differences between the mean of the preand post-applying of the two experimental groups (G3 + G4) that used the motion infographic in the observation card $(n=54)$.

\begin{tabular}{|l|l|l|c|c|}
\hline Groups & $\begin{array}{l}\text { Arithmetic } \\
\text { mean }\end{array}$ & $\begin{array}{l}\text { Standard } \\
\text { deviation }\end{array}$ & T & $\begin{array}{l}\text { Significance } \\
\text { level at } \alpha<0.05\end{array}$ \\
\hline Pre & 39.1296 & 24.14660 & \multirow{2}{*}{-9.942} & $\begin{array}{c}0.000 \\
\text { (Significant) }\end{array}$ \\
\hline Post & 79.0185 & 34.01525 & & \\
\hline
\end{tabular}

By reviewing the results in table (6), it is clear that the calculated $(\mathrm{t})$ value is $(-$ 9.942), which is greater than the tabulated $(t)$ value at the level $(0.05)$. This indicates that there is a statistically significant difference at the significance level $(\alpha<0.05)$ between the average scores of the total sample members in the pre-applying, which is (39.1296) and the average scores of the sample members in the post-applying, which is (79.0185). This difference is in favor of the higher average, which is the average of the post applying scores, which indicates the existence of an effect of using the motion infographic type in developing the performance aspects of digital graphics skills compared to not using it in terms of the results of the observation card. Figure (6) shows the differences between the performance averages in favor of the post applying scores of the motion infographic in the observation card. 

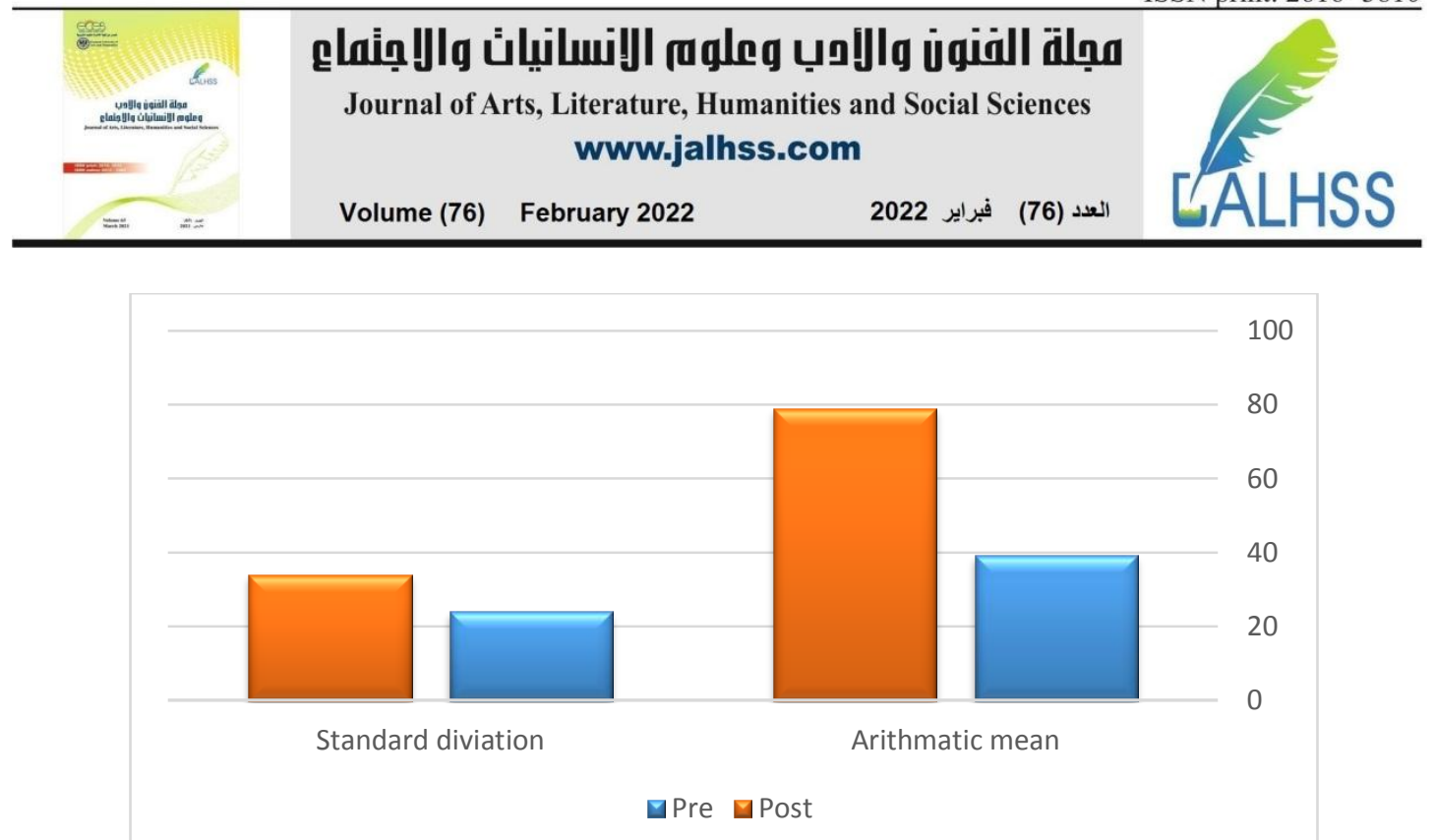

Figure 6: The significance of the differences between the mean of the pre and post applying of the two experimental groups (G3 + G4) that used the motion infographic in the observation card.

To confirm these differences in the performance aspects, the differences between the arithmetic averages of the results evaluation card scores were also compared in the pre and post applying of the two experimental groups (G3 + G4) that used the motion infographic, using a (Paired Sample T test). It is shown in table (7).

Table 7: Paired sample $T$ test to indicate the differences between the mean of the pre and post applying of the two experimental groups (G3 + G4) that used the motion infographic in the results evaluation card $(n=54)$.

\begin{tabular}{|l|l|l|c|c|}
\hline Groups & $\begin{array}{l}\text { Arithmetic } \\
\text { mean }\end{array}$ & $\begin{array}{l}\text { Standard } \\
\text { deviation }\end{array}$ & T & $\begin{array}{l}\text { Significance } \\
\text { level at } \alpha<0.05\end{array}$ \\
\hline Pre & 28.5370 & 16.95356 & -12.030 & $\begin{array}{c}0.000 \\
\text { (Significant) }\end{array}$ \\
\hline Post & 59.5556 & 17.86603 & &
\end{tabular}

By reviewing the results of table (7), it becomes clear that the calculated (T) value amounted to $(-12.030)$, which is greater than the tabular $(\mathrm{T})$ value at the $(0.05)$ level. That indicates that there is a statistically significant difference at the significance level $(\alpha<0.05)$ between the average scores of the total sample members in the pre-applying, which is (28.5370) and the average scores of the sample members in the post-applying, which is (59.5556) in favor of the higher average, which is the average scores of the post-applying. This indicates that there is an effect of using the motion infographic type in developing the performance aspects of digital graphics skills, compared to not using it in terms of the results of the results evaluation card. Figure (7) shows the differences between the performance averages in favor of the post applying scores of the motion infographic in the results evaluation card. 

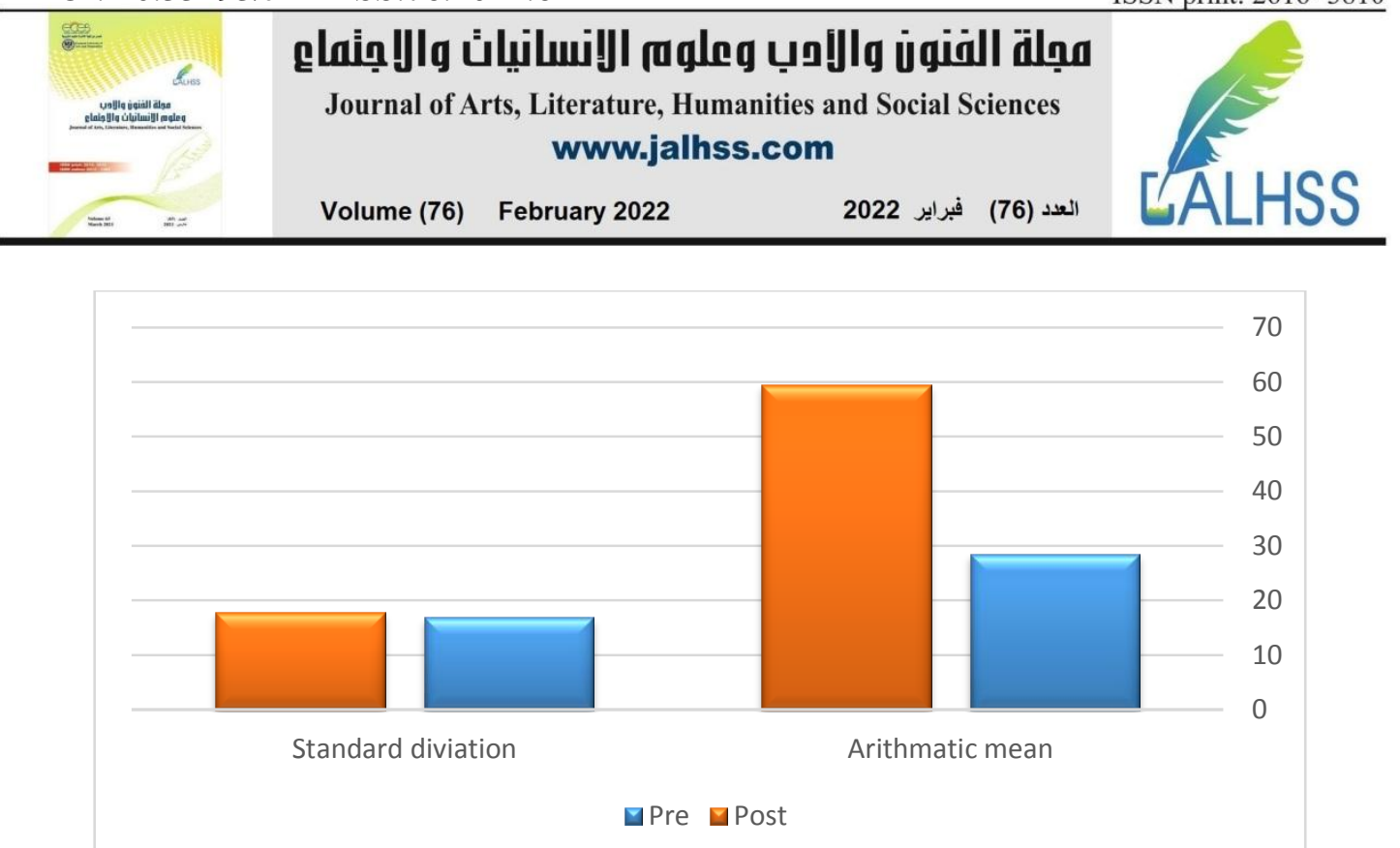

Figure 7: The significance of the differences between the mean of the pre and post applying of the two experimental groups (G3 + G4) that used the motion infographic in the results evaluation card.

Finally, in order to identify the effect of the difference in using static and motion infographics types in developing the performance aspects of digital graphics design skills, the researcher used an independent sample $T$ test to calculate the significance of the difference between the average performance scores in the two experimental groups $(\mathrm{G} 1+\mathrm{G} 2)$ that used static infographics, and the two experimental groups (G3 + G4) that used motion infographics, in the post applying degrees of the observation card and the results evaluation card, as shown in the tables (8) and (9).

Table 8: Results of the independent samples t-test to indicate the differences between the mean scores of the experimental groups (G1 + G2) and the experimental groups (G3 +

G4) in the post-applying of the observation card $(n=109)$

\begin{tabular}{|l|l|l|l|c|c|}
\hline Groups & $\#$ & $\begin{array}{l}\text { Arithmetic } \\
\text { mean }\end{array}$ & $\begin{array}{l}\text { Standard } \\
\text { deviation }\end{array}$ & T value & $\begin{array}{l}\text { Significance } \\
\text { level at } \\
\alpha<0.05\end{array}$ \\
\hline G1+G2 & 55 & 68.6182 & 28.26494 & \multirow{2}{*}{-1.737} & $\begin{array}{l}0.085 \text { (Not } \\
\text { significant) }\end{array}$ \\
\hline
\end{tabular}

Table 9:Results of the independent samples t-test to indicate the differences between the mean scores of the experimental groups (G1 + G2) and the experimental groups (G3 +

G4) in the post-applying of the results card $(n=109)$

\begin{tabular}{|l|l|l|l|l|c|}
\hline Groups & $\#$ & $\begin{array}{l}\text { Arithmetic } \\
\text { mean }\end{array}$ & $\begin{array}{l}\text { Standard } \\
\text { deviation }\end{array}$ & T value & $\begin{array}{l}\text { Significance } \\
\text { level at } \\
\alpha<0.05\end{array}$ \\
\hline G1+G2 & 55 & 50.5455 & 15.75133 & -2.794 & $\begin{array}{l}0.162 \text { (Not } \\
\text { significant) }\end{array}$ \\
\hline G3+G4 & 54 & 59.5556 & 17.86603 & &
\end{tabular}

It is clear from tables (8) and (9) that there are no statistically significant differences at the level of significance $(\alpha<0.05)$ between the averages of the two experimental groups $(\mathrm{G} 1+\mathrm{G} 2)$ that will study using the static infographic type, and the two experimental groups $(\mathrm{G} 3+\mathrm{G} 4)$ that will study using the motion infographic type in the post-applying degrees of the observation card and the results evaluation 


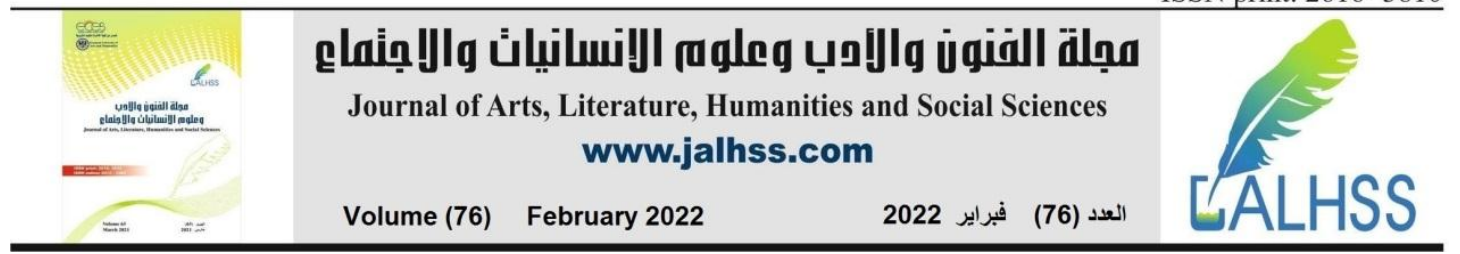

card. The $(\mathrm{t})$ value $(-1.737)$ at the significance level $(0.085)$, which is greater than the level of statistical significance (0.05) for the results of the observation card, and the value of $(t)$ was $(-2.794)$ at the significance level $(0.162)$, which is greater than the level of statistical significance (0.05), for the results of the results evaluation card. Figures (8) and (9) clarify the convergence of differences between the performance averages of the two experimental groups $(\mathrm{G} 1+\mathrm{G} 2)$ and the two experimental groups (G3 + G4) in the post applying, and there are no statistically significant differences between them, whether for the observation card or the results evaluation card.

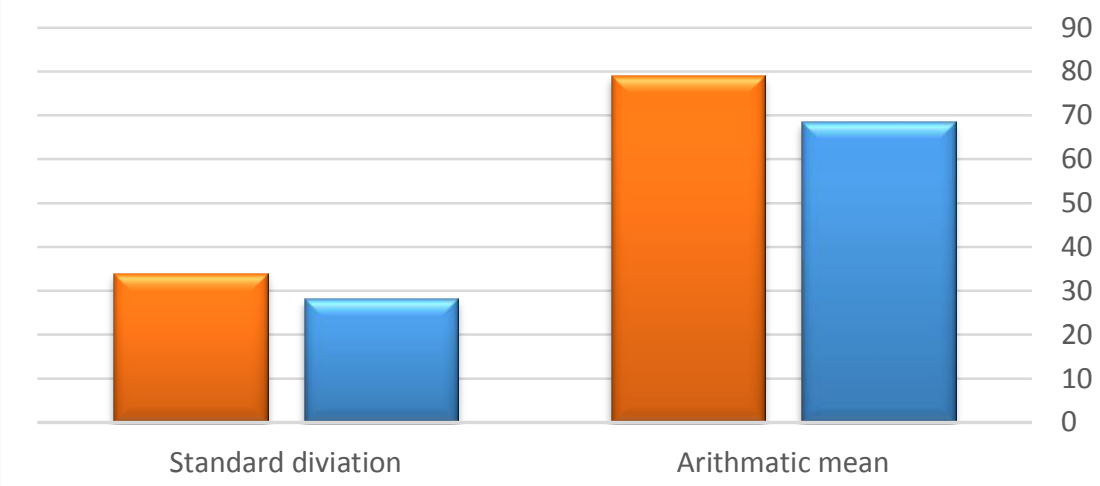

$\mathrm{G} 1+\mathrm{G} 2 \mathrm{G} 3+\mathrm{G} 4$

Figure 8: The significance of the differences between the mean scores of the experimental groups (G1 + G2) and the experimental groups (G3 + G4) in the postapplying of the observation card.

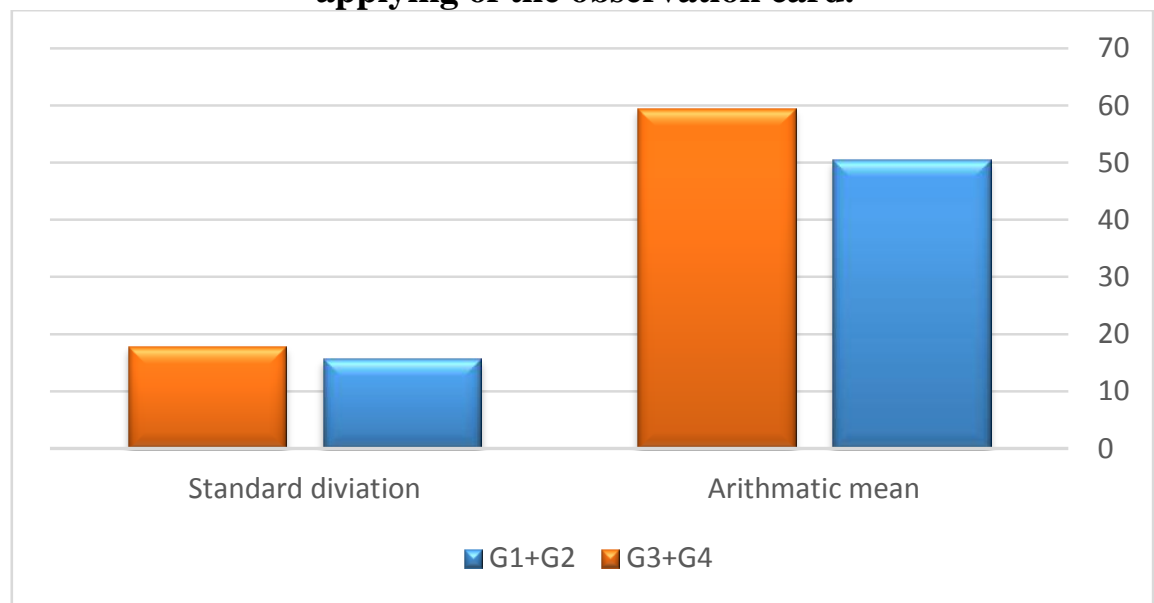

Figure 9:The significance of the differences between the mean scores of the experimental groups (G1 + G2) and the experimental groups (G3 + G4) in the post-applying of the results evaluation card.

In light of the above, the hypothesis was accepted, which states that there are no statistically significant differences at the level $(\alpha<0.05)$ between the two types of infographics in terms of presentation (static, motion) in developing the performance aspects of digital graphics design skills for students of Educational Technology in experimental groups at the University of Jeddah. 


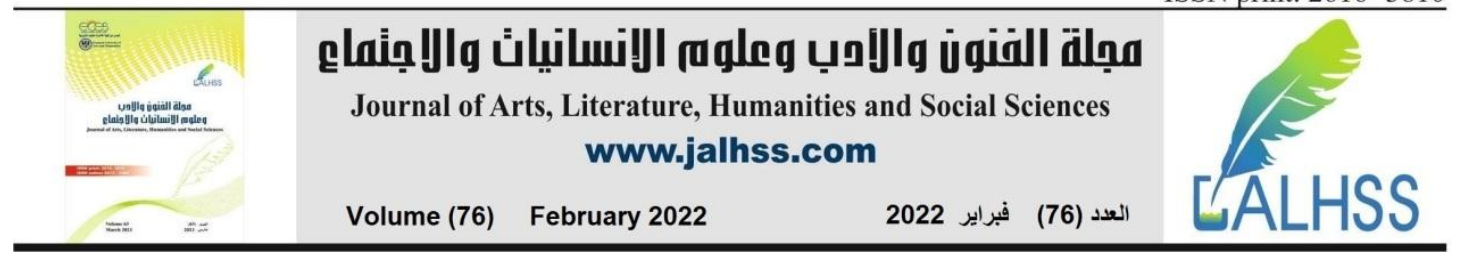

\subsection{Results of the Third Hypothesis}

To test third hypothesis, the researcher used the results of comparing the motivation scale of the two experimental groups $(\mathrm{G} 1+\mathrm{G} 2)$ that study using the static infographic type, and the two experimental groups $(\mathrm{G} 3+\mathrm{G} 4)$ that study in the motion infographic type, with the results of the motivation scale of the same groups, to identify the effect of the educational infographic type (static and motion) on developing motivation towards digital graphics.

The researcher used a (Paired Sample T test) to detect the effect of using a static infographic type in developing motivation towards digital graphics, by calculating the significance of the difference between the mean scores of the motivation scale in the pre and post applying of the two experimental groups $(\mathrm{G} 1+\mathrm{G} 2)$ which used the static infographic, as shown in table (10).

Table 10: Paired sample $T$ test to indicate the differences between the mean of the preand post-applying of the two experimental groups $(\mathrm{G1}+\mathrm{G2})$ that used the static infographic in the motivation scale $(n=55)$.

\begin{tabular}{|l|l|l|c|c|}
\hline Groups & $\begin{array}{l}\text { Arithmetic } \\
\text { mean }\end{array}$ & $\begin{array}{l}\text { Standard } \\
\text { deviation }\end{array}$ & T & $\begin{array}{l}\text { Significance } \\
\text { level at } \alpha<0.05\end{array}$ \\
\cline { 1 - 2 } Pre & 61.0364 & 9.82997 & \multirow{2}{*}{-6.357} & $\begin{array}{c}0.000 \\
\text { (Significant) }\end{array}$ \\
\hline Post & 70.1091 & 7.17421 & &
\end{tabular}

By reviewing the results of Table No. (10), it becomes clear that the calculated (T) value amounted to (-6.357), which is greater than the tabular (T) value at the level (0.05). This indicates that there is a statistically significant difference at the significance level $(\alpha<0.05)$ between the average scores of the total sample members in the pre-applying, which is (61.0364), and the average scores of the sample members in the post-applying, which is (70.1091) in favor of the higher average, which is the average scores of the post-applying. This indicates that there is an effect of using static infographic type in developing motivation towards digital graphics compared to not using it, according to the results of the motivation scale. Figure (10) shows the differences between the averages of motivation in favor of the post-applying degrees of the static infographic. 

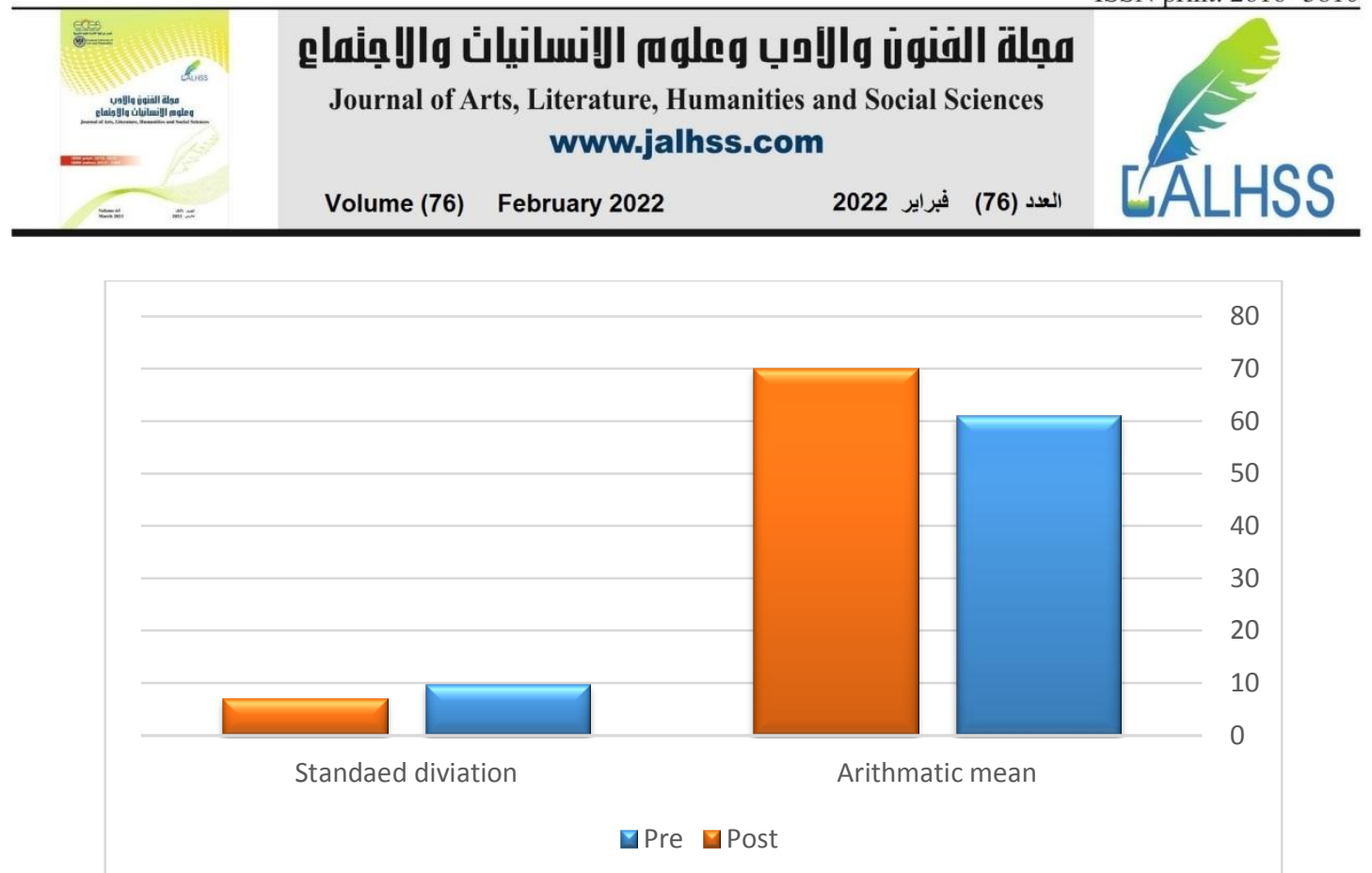

Figure 10:The significance of the differences between the mean of the pre and post applying of the two experimental groups (G1 + G2) that used the static infographic in the motivation scale.

The effect of using the motion infographic style in developing the motivation towards digital graphics was identified through calculating the significance of the difference between the mean scores of the students' motivation in the pre and post applying of the two experimental groups $(\mathrm{G} 3+\mathrm{G} 4)$ that used the motion infographic using (Paired Sample T test), as shown in table (11).

Table 11: Paired sample $T$ test to indicate the differences between the mean of the pre and post applying of the two experimental groups (G3 + G4) that used the motion infographic in the motivation scale $(n=54)$.

\begin{tabular}{|l|l|l|l|c|}
\hline Groups & $\begin{array}{l}\text { Arithmetic } \\
\text { mean }\end{array}$ & $\begin{array}{l}\text { Standard } \\
\text { deviation }\end{array}$ & T & $\begin{array}{l}\text { Significance } \\
\text { level at } \alpha<0.05\end{array}$ \\
\cline { 1 - 2 } Pre & 64.5000 & 11.31829 & \multirow{2}{*}{-6.357} & $\begin{array}{c}0.000 \\
\text { (Significant) }\end{array}$ \\
\hline Post & 69.5000 & 7.32210 & &
\end{tabular}

By reviewing the results in table (11), it becomes clear that the calculated (t) value is (-6.357), which is greater than the tabulated $(t)$ value at the level $(0.05)$. This indicates that there is a statistically significant difference at the significance level $(\alpha<0.05)$ between the average scores of the total sample members in the pre-applying, which is (64.50004) and the average scores of the sample members in the postapplying, which is (69.5000) in favor of the higher average, which is the average of the post-applying scores. This indicates that there is an effect of using the motion infographic style in developing the motivation towards digital graphics, compared to the lack of its use in the academic achievement of students. Figure (11) shows the differences between the averages of motivation in favor of the post-applying degrees of the motion infographic. 

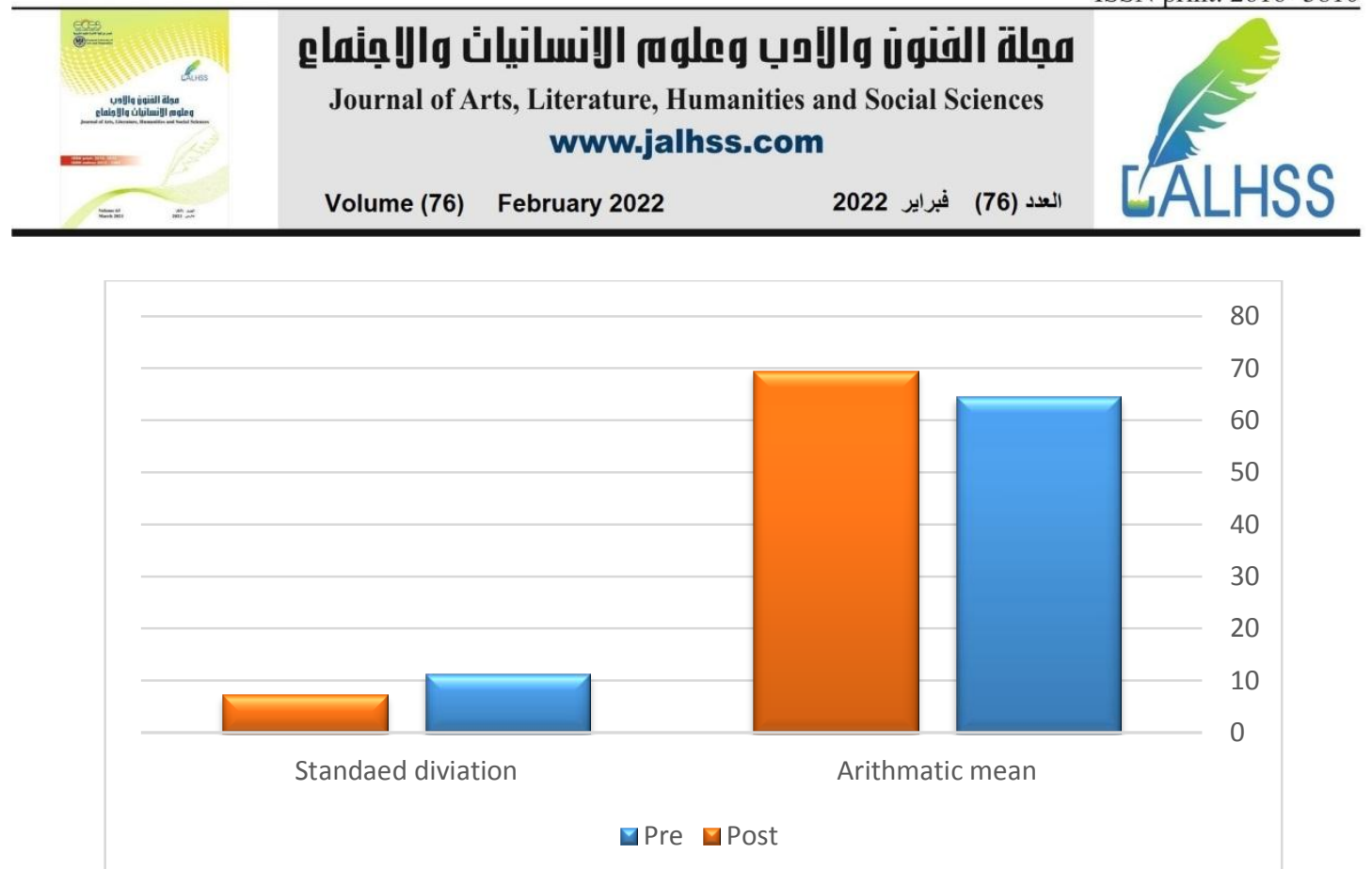

Figure 11: The significance of the differences between the mean of the pre and post applying of the two experimental groups (G3 + G4) that used the motion infographic in the motivation scale.

Finally, in order to identify the effect of the difference in using static and motion infographics types in developing motivation towards digital graphics, the researcher used an independent sample $\mathrm{T}$ test to calculate the significance of the difference between the mean scores of students' motivation in the two experimental groups (G1 + G2) that used static infographics, and the two experimental groups (G3 + G4) that used motion infographics, in the post-applying degrees of the motivation scale, as shown in table (12).

Table 12: Results of the t-test for independent samples to indicate the differences between the mean scores of the experimental groups $(\mathrm{G1}+\mathrm{G2})$ and the experimental groups (G3 + G4) in the post-applying of the motivation scale $(n=109)$.

\begin{tabular}{|l|l|l|l|l|l|}
\hline Groups & $\#$ & $\begin{array}{l}\text { Arithmetic } \\
\text { mean }\end{array}$ & $\begin{array}{l}\text { Standard } \\
\text { deviation }\end{array}$ & T value & $\begin{array}{l}\text { Significance } \\
\text { level at } \\
\alpha<0.05\end{array}$ \\
\cline { 1 - 4 } G1+G2 & 55 & 70.1091 & 7.17421 & 0.439 & $\begin{array}{l}0.662 \\
\text { (Not } \\
\text { significant) }\end{array}$ \\
\hline
\end{tabular}

It is clear from table (12) that there are no statistically significant differences at the level of significance $(\alpha<0.05)$ between the averages of the two experimental groups $(\mathrm{G} 1+\mathrm{G} 2)$ that will study using static infographic type, and the two experimental groups (G3 + G4) that will study using motion infographic type in the degrees of the post applying of the motivation scale. The $(t)$ value is $(0.439)$ at the significance level (0.662), which is greater than the statistical significance level (0.05). Figure (12) shows the convergence of differences between the averages of the two experimental groups $(\mathrm{G} 1+\mathrm{G} 2)$ and the two experimental groups $(\mathrm{G} 3+\mathrm{G} 4)$, and there are no statistically significant differences between them. 

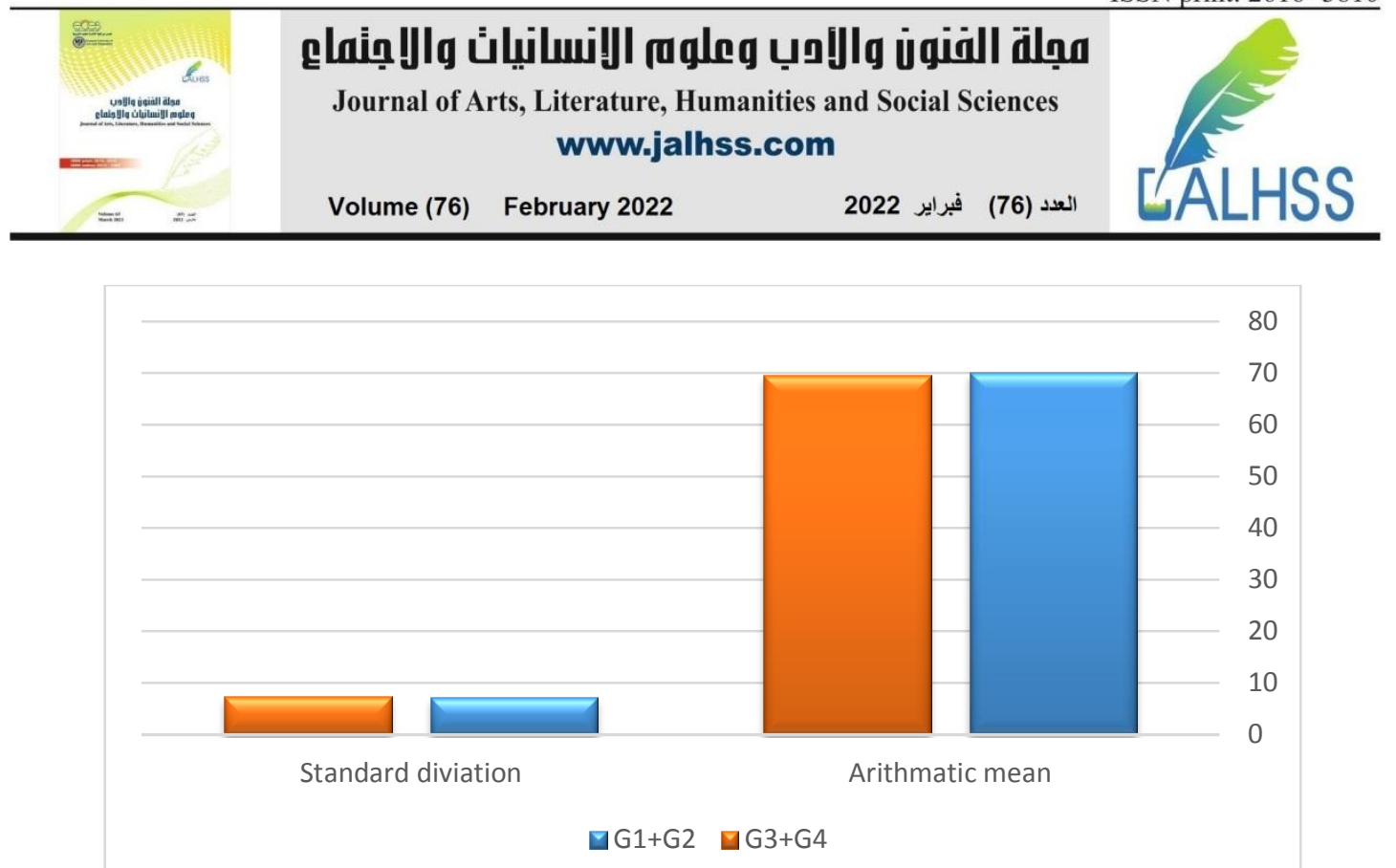

Figure 12: The significance of the differences between the mean scores of the experimental groups (G1 + G2) and the experimental groups (G3 + G4) in the postapplying of the motivation scale.

In light of the above, the hypothesis was accepted, which states that there are no statistically significant differences at the level $(\alpha<0.05)$ between the two types of infographics in terms of presentation method (static, motion) in developing motivation towards digital graphics among students of Educational Technology in the experimental groups in the University of Jeddah.

\section{Discussion}

The results related to the first hypothesis showed that the mean test scores of students in the two experimental groups $(\mathrm{G} 1+\mathrm{G} 2)$ that used static infographics are close to the mean scores of students' test in the two experimental groups (G3 + G4) that used motion infographics In the post-applying of the achievement test, and there are no statistically significant differences between them. However, there is an effect of using both static and motion infographics style in developing the cognitive aspects of digital graphics skills in the post test compared to the pre-test, i.e. without using technology in Academic achievement of students.

It can be noted that these results were consistent with some studies that indicated that there were no statistically significant differences between the static and motion infographics types on students' academic achievement, while it confirmed the effectiveness of applying the static and motion infographics type in developing academic achievement compared to the results of students who study in the traditional (ordinary) ways. Among these studies, the study of Shay'i and Al-Zahrani (2018); which clarified that there was no effect of the difference between the two types of infographics (static and motion) in the development of academic achievement in the computer course among female students of the second year of secondary school in the city of Riyadh. While the studies of Al-Shay'i and Al-Zahrani (2018), Morsi (2017), confirmed, Al-Mohammadi (2017) and Ozdamlı et al. (2016) on the effectiveness of the educational infographic applying and its positive effects on students' cognitive achievement and their attitude towards the learning environment compared to traditional educational environments. While the results of the current study differed 


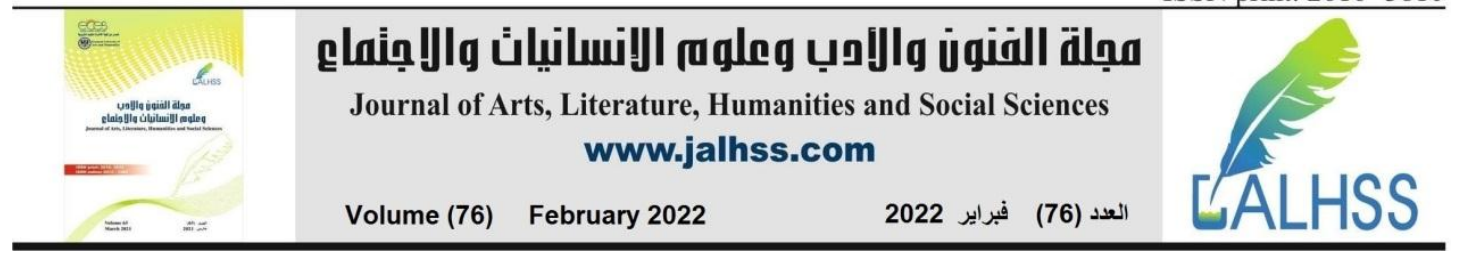

with Shaltout \& Fatani study. (2017), Darwish and Al-Dakhini (2015), and Sears (2012), which indicated the superiority of the students of the experimental group that used the static infographic style over the experimental group that used the motion pattern, as well as Abu Oreiban (2017), Crooks, Lankow \& Ritchie (2012), which indicated the superiority of the students of the experimental group that used the motion infographic type over the experimental group that used the static type.

The researcher can explain the difference in the result of his study with the study of Darwish and Al-Dakhini (2015) that the sample on which the experiment was applied in the study of Darwish and Al-Dakhini are children with autism. As it is known that this category finds it difficult to install the parts to be a general or comprehensive picture, which is the basis of the motion infographic style, in which the information is fragmented into non-static segments. In addition to their hypermobility and inability to prolong their sitting period and focus their eyes for a long time; thus, some stages may disappear without having paid attention to them, which gives superiority to the static type over the motion type in their study, while the sample of the current study are students of Educational Technology at the University of Jeddah who are able to deal with the two types of infographics equally without difference. The difference in the result of the study with the study of Sears (2012) can also be explained by the fact that the results of Sears in particular differed according to the personal variables of the students, as static infographics were more effective for males, for example, while motion infographics were more effective for females. This is not found in a sample of our study, which consisted of males only, in which the researcher sought to ensure that the sample was similar in terms of gender and convergence in terms of age group.

The results related to the second hypothesis showed that the average scores of the observation card and the results evaluation card for the students in the two experimental groups $(\mathrm{G} 1+\mathrm{G} 2)$ that used the static infographic are close to the average scores of the observation card and the results evaluation card for students in the two experimental groups $(\mathrm{G} 3+\mathrm{G} 4)$ that used motion infographics, in the post applying of the two cards. There are no statistically significant differences between them. However, there is an effect of using both static and motion infographics type in developing the performance aspects of digital graphics skills in the post-test compared to the pre-test, that is, without using technology in the academic achievement of students.

It can be noted that these results were consistent with some studies that indicated that there were no statistically significant differences between the two types of fixed and mobile infographics on the performance aspects, while they emphasized the effectiveness of applying the static and motion infographics type in developing performance compared to the results of students who study with traditional methods (ordinary). Among these studies are Al-Shay'i and Al-Zahrani (2018), Abu al-Dahab (2018), Morsi (2017), Kaya-Hamza \& Beheshti-Fezile (2017), Al-Mohammadi (2017), Ozdaml et al. (2016), and Vanichvasin (2013). Where they emphasized the effectiveness of applying the educational infographic with its types, static or motion, or vertical or horizontal, and others in developing the performance aspects of students 


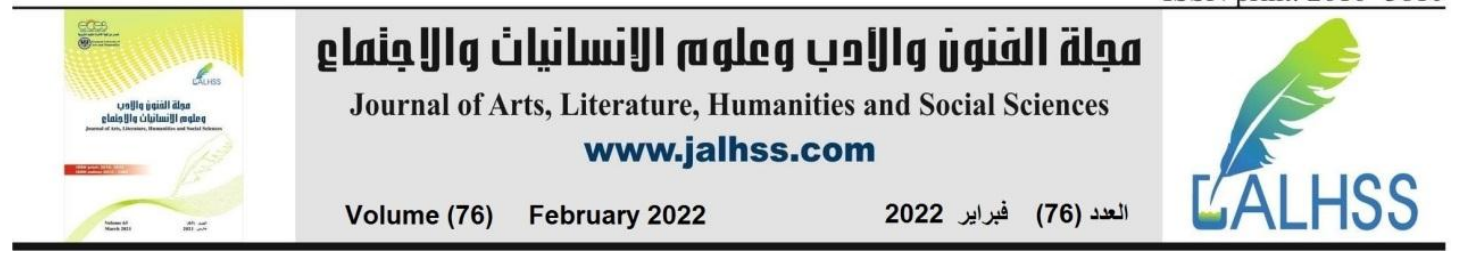

and its positive effects on the performance skills of students, its effectiveness in communicating and facilitating information and skills, and its effectiveness as a visual communication tool and an educational tool to promote effective learning, training students and improving their performance. While the results of the current study differed with the study of Shaltout \& Fatani (2017), Darwish and Al-Dakhini (2015), and Sears (2012), which indicated the superiority of the students of the experimental group that used the static infographic type over the experimental group that used the motion type, as well as the study of Abu Oreiban (2017) and Crooks, Lankow \& Ritchie (2012). Those studies indicated that the experimental group that used the motion infographic type outperformed the experimental group that used the static type. This difference can be explained by the different characteristics and describtions of the current study sample with the study of Darwish and Al-Dakhini (2015), which dealt with children with autism, and Sears (2012), whose results differed according to the personal variables of the students in terms of gender.

The results related to the third hypothesis showed that the average scores of the motivation scale for students in the two experimental groups $(\mathrm{G} 1+\mathrm{G} 2)$ that used the static infographic, are close to the average score of the motivation scale for students in the two experimental groups $(\mathrm{G} 3+\mathrm{G} 4)$ that used the motion infographic in the postapplying of the scale, and there are no statistically significant differences between them. However, there is an effect of using both static and motion infographics type in developing motivation towards digital graphics in the post test compared to the pretest, that is, without using technology in academic, in the student's achievement.

It can be noted that these results were consistent with some studies that indicated the effectiveness of applying the static and motion infographic type in developing motivation and arousing enthusiasm and suspense among students compared to the results of students who study by traditional (ordinary) methods. These studies include Morsi (2017), Kaya-Hamza \& Beheshti-Fezile (2017), Al-Mohammadi (2017), Ozdaml et al. (2016), Yildirim (2016) and Vanichvasin (2013). This indicates the effectiveness of applying the educational infographics with its various types: static or motion, or vertical or horizontal, and others in developing students' motivation towards digital graphics. Using infographics in general in education, regardless of the timing and type of presentation, provides the students with a general and attractive overview of the presented course and how to study it, which makes it more related to the educational content, which will makes students more willing to achieve learning goals. This will help them in changing their attitudes and motivation towards the learning environment. They have also indicated the effectiveness of this technology and its importance in teaching as one of the most interests and attractive essential learning materials, which makes learning using it more sustainable.

\section{Conclusion}

The aim of this research is to investigate the effect of two types of infographics in terms of presentation in developing the cognitive and performance aspects of digital graphics design skills and motivation towards them among students of Educational Technology at the University of Jeddah. Infographics are more understandable, more 


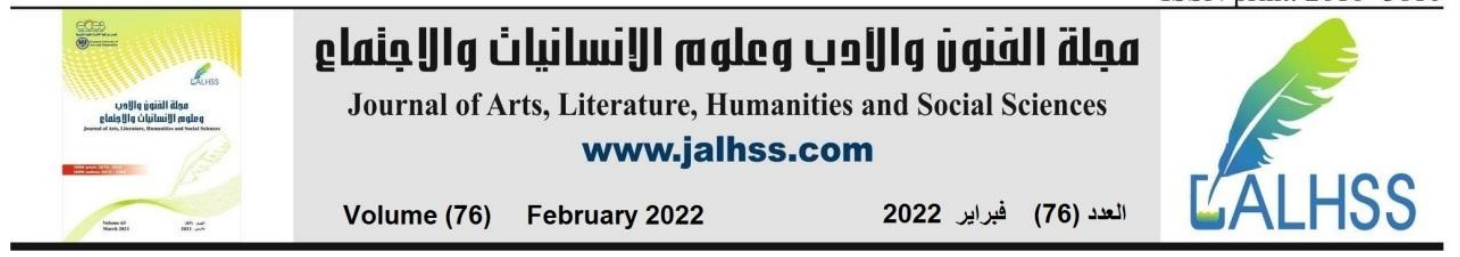

satisfying for students, and easier to stay in their mind, which indicates its great effectiveness in the educational process compared to the usual traditional process. The static and motion infographic types provides the opportunity for the learner to have an active positive role in obtaining knowledge, and linking it to his previous knowledge, which contributes to the development of cognitive aspects, unlike traditional education that focuses on the teacher and limits learner's role.

The static or motion infographic technology corresponds to the students' desires to use new ways to employ technology in education, which encourages students to learn different subjects with passion and motivation and increases their tendency towards using it in education. Infographic technology overcomes the monotony and boredom of the traditional teaching method. Images, video, animated shapes, colors, 3-D formats, and other multiple kinetic, audio and visual media make the learning environment enhanced and close to reality, which contributes to the development of students' attitudes towards using this technology and realizing its importance. Infographic technology provides - and through the Blackboard system - educational content in a fragmented and coherent manner, with the ability to refer to it at any time and any place, which makes it easier for students and increases their tendency towards this technology.

The motion and static infographic technology is consistent with the principles of the constructivist theory, both of which focus on the learner's positivity and interaction with the educational subjects, through thinking and activity, as well as the presence of an active role for the researcher and teachers in guiding the students, which helped the learners to acquire the skill and improve their performance production. The continuous interaction between students among each other through the Blackboard system, on which videos and static infographics have been uploaded, and providing the means of continuous support and guidance through them, which helps to find solutions to the problems faced by students in practice, and thus improves their performance. The technology offers the possibility of individual self-learning, which enables students to overcome fear and shame of wrong performance, which is reflected positively on performance.

In light of these results, the research recommended the necessity of employing static and motion infographic technology in teaching the digital graphics course and other courses, and in presenting the cognitive and performance structure of the course content to students, due its significant impact on developing the performance and cognitive skills and raising the efficiency of education compared to traditional methods.

\section{References}

1. Abu Oreiban, Abeer (2017) The Effectiveness of Employing Infographic Technology (static- Motion) in Developing Genetic Problem Solving Skills in Life Sciences for Tenth Grade Students in Gaza, Master Thesis, Gaza.

2. Abu Osba, Shaima Mohammed (2015). The effect of using the infographic strategy on the achievement of fifth graders, their attitudes towards science, and their motivation to learn it. Unpublished Master's Thesis, An-Najah National University, Palestine. 


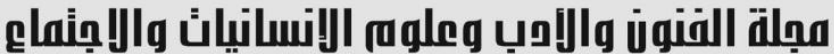 \\ Journal of Arts, Literature, Humanities and Social Sciences www.jalhss.com}

Volume (76) February 2022

2022

العدد (76) (2) (2)

3. Abu Zeid, Salah Mohamed Gomaa (2016). Using infographics in teaching geography to develop the achievement and visual thinking skills of secondary school students. Journal of the Educational Society for Social Studies, 79, pp. 138-198.

4. Afana, Ghufran Bakr Ibrahim, and Al-Waeli, Suad Abdel Karim (2016). The impact of teaching according to the two types of audio-visual learning on developing the oral expressive performance and on motivation toward achievement in the Arabic language among the fourth grade students in Zarqa. Journal of Educational Sciences Studies, 2 (43), 747-762.

5. Ahmed, Mohamed Sayed Jaber; Youssef, Walid Mohamed; Faris, Naglaa Mohammed; and Ismail, Abdel Raouf Mohamed (2018). Standards for designing and producing educational infographics. South Valley University International Journal of Educational Sciences, 1, 1-19.

6. Akkoyunlu, B., \& Kibar, P. N. (2014, October). A new approach to equip students with visual literacy skills: Use of infographics in education. In European Conference on Information Literacy (pp. 456-465). Springer, Cham.

7. Al-Ghamdi, Mona bint Saad (2018). The impact of demographic variables on the level of awareness of female mathematics teachers in the city of Riyadh with infographic technology and the degree to which they possess the skills of its design. Journal of the Islamic University of Educational and Psychological Studies, 3 (26), 128-158.

8. Al-Jeriwi, Siham (2014). The effectiveness of using a proposed training program in developing the skills of designing electronic mental maps through infographic technology and the skills of visual culture among female teachers before service. Arab Studies in Education and Psychology, (40), pp. 13-74.

9. Al-Mohammadi, N. (2017). Effectiveness of using infographics as an approach for teaching programming fundamentals on developing analytical thinking skills for high school students in the city of Makkah in Saudi Arabia. Global Journal of Educational Studies, 3(1), 22-42.

10. Alshay'i, Hessa bint Mohammed; and Al-Zahrani, Ghadeer bint Ali (2018). The effect of two types of infographics on developing academic achievement in the computer course for female students in the second year of secondary school in Riyadh. Al-Fath Magazine, 73, pp. 84-117.

11. Ashman, R., \& Patterson, A. (2015). Seeing the big picture in services marketing research: infographics, SEM and data visualization. Journal of Services Marketing, 29(6/7), 613-621.

12. Darwish, Muhammad (2016). The effectiveness of using infographic technology on learning the skill performance and cognitive achievement of the long jump competition. Scientific Journal of Physical Education, 77, pp. 312-342.

13. Gebre, E. H., \& Polman, J. L. (2015). Towards critical appraisal of infographics as scientific inscriptions. Journal of research in science teaching, 52(6), 868-893.

14. Hassan, Amal (2016). The effect of different patterns of informational design (infographic) on the achievement and the survival of the effect of learning among students with learning difficulties in geography in the preparatory stage and their attitude towards the subject. Unpublished Master's Thesis, Ain Shams University, Egypt.

15. Ibn Manzur (1998). Lisan Al Arab, 6/4, article: trace. 


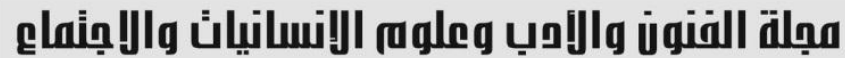 \\ Journal of Arts, Literature, Humanities and Social Sciences www.jalhss.com \\ Volume (76) February 2022 \\ العدد (76) فبراير 2022}

16. Kaya-Hamza, A. T. O. S., \& Beheshti-Fezile, F. S. M. (2017). An Investigation toward Advantages, Design Principles and Steps of Infographics in Education. Il Ponte, 73(7), 157-166.

17. Khadija, Bin Saadia, and Al-Zahraa, Mediani Fatima (2015). Motivation for achievement and its relationship to academic achievement among students who are going to obtain the baccalaureate degree. Master's Thesis, Akli Mohand Olhadj University Bouira -, Algeria.

18. Kos, B. A., \& Sims, E. (2014). Infographics: The new 5-paragraph essay. In 2014 Rocky Mountain Celebration of Women in Computing. Laramie, WY, USA.

19. Krum, R. (2013). Cool infographics: Effective communication with data visualization and design. John Wiley \& Sons.

20. Lankow, J., Ritchie, J., \& Crooks, R. (2012). Infographics: The power of visual storytelling. John Wiley \& Sons.

21. Morsi, Ashraf Ahmed Abdel Latif (2017). The effect of the interaction between the two types of presenting and timing of the infographic in the e-learning environment on the achievement and attitude towards the learning environment among secondary school students. Journal of Educational Sciences, 2 (7), pp. 42-121.

22. Noh, M. A. M., Shamsudin, W. N. K., Nudin, A. L. A., Jing, H. F., Daud, S. M., Abdullah, N. N. N., \& Harun, M. F. (2015). The use of infographics as a tool for facilitating learning. In International colloquium of art and design education research (iCADER 2014) (pp. 559-567). Springer, Singapore.

23. Obeidat, Thouqan and Abdel Haq, Kayed and Adas, Abdel Rahman (1996). Scientific research: concept, tools, and methods. Riyadh: Osama Publishing House.

24. Ott, C., Robins, A., \& Shephard, K. (2014). An infographic to support students' selfregulated learning. In Proceedings of the 14th Koli Calling International Conference on Computing Education Research (pp. 177-178). ACM.

25. Ozdamli, F., \& Ozdal, H. (2018). Developing an instructional design for the design of infographics and the evaluation of infographic usage in teaching based on teacher and student opinions. EURASIA Journal of Mathematics, Science and Technology Education, 14(4), 1197-1219.

26. Ozdaml1, F., Kocakoyun, S., Sahin, T., \& Akdag, S. (2016). Statistical reasoning of impact of infographics on education. Procedia Computer Science, 102, 370-377.

27. Purchase, H., \& Moere, A. (2011). On the role of design in information visualization. research gate.

28. Sears, R. B. (2012). Evaluating the effectiveness of multimedia information graphics in the learning environment. Texas A\&M University-Commerce.

29. Smiciklas, M. (2012). The power of infographics: Using pictures to communicate and connect with your audiences. Que Publishing.

30. Vanichvasin, P. (2013). Enhancing the quality of learning through the use of infographics as visual communication tool and learning tool. In Proceedings ICQA 2013 international conference on QA culture: Cooperation or competition (p. 135).

31. Yildirim, S. (2016). Infographics for Educational Purposes: Their Structure, Properties and Reader Approaches. Turkish Online Journal of Educational TechnologyTOJET, 15(3), 98-110. 